\title{
Preparation and Characterization of a Monocyclopentadienyl Osmium-Allenylcarbene Complex
}

Miguel A. Esteruelas, * Yohar A. Hernández, Ana M. López, and Enrique Oñate.

Departamento de Química Inorgánica, Instituto de Ciencia de Materiales de Aragón, Universidad de Zaragoza - CSIC, 50009 Zaragoza, Spain

\section{X-ray Crystallographic Data for 2}

An orange crystal of approximate dimensions $0.20 \times 0.14 \times 0.10 \mathrm{~mm}$ was mounted on a glass fiber and transferred to a Bruker CCD platform diffractometer. The SMART program package was used to determine the unit-cell parameters and for data collection $(10 \mathrm{sec} /$ frame scan time for a sphere of diffraction data at $50 \mathrm{kV}, 30 \mathrm{~mA})$. The raw frame data was processed using SAINT and SADABS to yield the reflection data file. Subsequent calculations were carried out using the SHELXLTL program. The diffraction symmetry was $2 / \mathrm{m}$ and the systematic absences were consistent with the centrosymmetric monoclinic space group $\mathrm{P} 2{ }_{1} / \mathrm{n}$ which was later determined to be correct.

The structure was solved by Patterson and refined on $\mathrm{F}^{2}$ by full-matrix least-squares techniques. The most satisfactory refinement required the complete molecule be treated as disordered and included using two components with partial occupancy factors (57/43) showing the stereochemistry illustrated in the next Figure (enantiomers A and B).
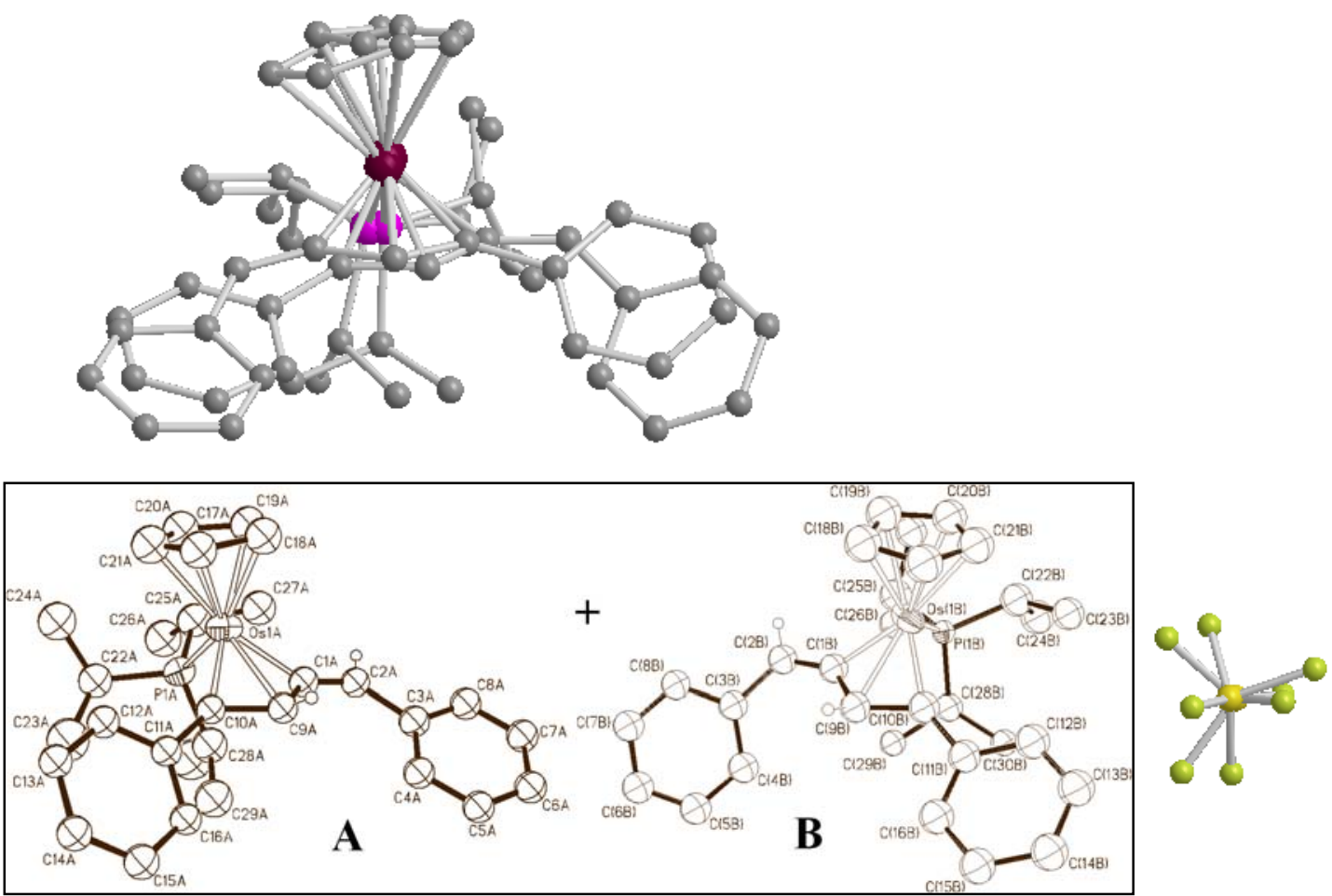
To solve this disorder two strategies were followed:

a) search for a bigger unit cell with the SMART program package. The careful study of the complete frame data set did not show unindexed reflections $(I / \sigma \geq 2)$. The molecule was also refined in the monoclinic $\mathrm{P} 2{ }_{1}$ and $\mathrm{Pn}$, and in the triclinic $\mathrm{P} 1$ and $\mathrm{P}-1$ space groups to tray to improve the refinement but no positive results were obtained, and finally the $\mathrm{P} 2{ }_{1} / \mathrm{n}$ space group was chosen.

In the last cycles of refinement the related geometrical parameters of both disordered molecules were restrained to refine freely with the same values (within the standard deviation) using an isotropic model for all atoms (except osmium and phosphorous). Hydrogen atoms were included using a riding model.

b) change the anion to modify the crystallization system but, unfortunately, we did not obtain crystals suitable for an X-ray experiment.

References.

1. SMART Software Users Guide, Version 5.625, Bruker Analytical X-Ray Systems, Inc.; Madison, WI 2000.

2. SAINT Software Users Guide, Version 6.1, Bruker Analytical X-Ray Systems, Inc.; Madison, WI 2000.

3. Sheldrick, G. M. SADABS, Version 2.0, Bruker Analytical X-Ray Systems, Inc.; Madison, WI 2000.

4. Sheldrick, G. M. SHELXTL Version 6.1, Bruker Analytical X-Ray Systems, Inc.; Madison, WI 2000. 
Crystal Data and Data Collection and Refinement for 2.

Crystal Data

formula

$\mathrm{C}_{30} \mathrm{H}_{38} \mathrm{BF}_{4} \mathrm{OsP}$

molecular wt

706.58

color and habit

orange, block

size, $\mathrm{mm}$

$0.20,0.14,0.10$

symmetry, space group

monoclinic, $\mathrm{P} 21 / \mathrm{n}$

$a, \AA$

$b, \AA$

10.2901(15)

$c, \AA$

$17.239(3)$

15.961(2)

$\beta,{ }^{\circ}$

$V, \AA^{3}$

98.652(3)

2799.2(7)

Z

$D$ calc, $\mathrm{g} \mathrm{cm}^{-3}$

4

1.677

Data Collection and Refinement

diffractometer

Bruker Smart APEX

$\lambda(\mathrm{Mo}-\mathrm{K} \alpha), \AA$

0.71073

monochromator

graphite oriented

scan type

$\omega$ scans

$\mu, \mathrm{mm}^{-1}$

4.657

$2 \theta$, range deg

3,58

temp, $\mathrm{K}$

$100.0(2)$

33796

no. of data collect

$6841\left(R_{\text {int }}=0.0474\right)$

no. of unique data

274/306

no. of params/restrains

0.0670

$R_{1}{ }^{\mathrm{a}}\left[F^{2}>2 \sigma\left(F^{2}\right)\right]$

0.1710

$\omega \mathrm{R}_{2}{ }^{\mathrm{b}}$ [all data]

1.184

$\mathrm{S}^{\mathrm{c}}$ [all data]

${ }^{\mathrm{a}} R_{1}(F)=\Sigma|| F_{\mathrm{o}}|-| F_{\mathrm{c}}|/ \Sigma| F_{\mathrm{o}} \mid .{ }^{\mathrm{b}} \omega R_{2}\left(\mathrm{~F}^{2}\right)=\left\{\Sigma\left[\omega\left(\mathrm{F}_{\mathrm{o}}{ }^{2}-F_{\mathrm{c}}{ }^{2}\right)^{2}\right] / \Sigma\left[\omega\left(F_{\mathrm{o}}\right)^{2}\right]\right\}^{1 / 2} \cdot{ }^{\mathrm{c}}$ Goof $=\mathrm{S}=\left\{\Sigma\left[F_{\mathrm{o}}{ }^{2}\right.\right.$ $\left.\left.\left.-F_{\mathrm{c}}{ }^{2}\right)^{2}\right] /(n-p)\right\}^{1 / 2}$, where $n$ is the number of reflections and $p$ is the number of refined parameters. 